\title{
Effect of Processing on Profenofos and Chlorpyrifos Residues in Cauliflower Curds
}

\author{
Tanuja Banshtu*, Surender Kumar Patyal and Sarswati Negi \\ Department of Entomology, Dr YS Parmar University of Horticulture and Forestry, Nauni, \\ Solan - 173230 Himachal Pradesh, India \\ *Corresponding author
}

\begin{tabular}{|c|}
\hline Keywords \\
\hline $\begin{array}{l}\text { Cauliflower, } \\
\text { Processing, } \\
\text { Profenofos, } \\
\text { Chlorpyrifos, Residues }\end{array}$ \\
\hline Article Info \\
\hline $\begin{array}{l}\text { Accepted: } \\
20 \text { September } 2018 \\
\text { Available Online: } \\
10 \text { October } 2018\end{array}$ \\
\hline
\end{tabular}

\section{A B S T R A C T}

Field and laboratory experiments were carried out to evaluate the effect of different decontamination processes on reduction of profenofos and chlorpyrifos residues in cauliflower curds like washing, cooking, washing plus cooking and dipping in chemical solutions after application of Profex 50EC (profenofos 50\%) and Lethal 20EC (chlorpyrifos 20\%) individually on the crop. Profex 50EC was applied twice at the rate of $0.8 \mathrm{ml} / \mathrm{L}$ and Lethal 20EC @ 2.50ml/L at 15 days interval on cauliflower crop. Cauliflower curds were collected at 0 ( 2 hours) and 3 days interval for profenofos and for chlorpyrifos curds were sampled at 0 ( 2 hours), 3 and 7 days after the last spray and subjected to decontamination processes. Washing of zero day contaminated curd samples provided 26.06-67.09\% relief from profenofos residues and 35.44-67.18\% relief from chlorpyrifos residues. Cooking degraded profenofos residues up to $37.17-67.57 \%$ and chlorpyrifos residues by $36.00-56.80 \%$. Washing plus cooking removed profenofos and chlorpyrifos residues up to $70 \%$ as compared to other processes and proved to be the best technique in removing the residues. Washing of curds with $2 \% \mathrm{NaOH}$ solution reduced the profenofos residues up to $67.09-70.30 \%$, whereas washing with $0.05 \%$ solution of $\mathrm{HCl}$ reduced the profenofos residues up to $63.48-65.52 \%$. Similarly chlorpyrifos residues were reduced to $40.00-67.18 \%$ after treatment with $2 \% \mathrm{NaOH}$ solution and up to $44.00-61.17 \%$ after treatment with $0.05 \% \mathrm{HCl}$ solution.

\section{Introduction}

Vegetables are the inseparable component of Indian cuisine and are consumed throughout the country in different forms and preparations. They are the major source of vitamins and nutrients; hence they fulfill the requirements of our balanced diet (Chandra $e t$ al., 2015). Cauliflower (Brassica oleracea var. botrytis L.) is an important cash crop of Himachal Pradesh which is infested by a large number of insect-pests and diseases (Sharma and Bhalla, 1964; Sharma, 1975; Bhalla and Pawar, 1977). The key pests of cauliflower are diamond back moth, leaf eating caterpillar and aphids (Regupathy et al., 1985; Patel et al., 1999) thus affecting both the quantity and quality of curds. In a desperate bid to save the crop farmers sometime apply the pesticide repeatedly and at higher doses hence the repeated and intensive use of insecticides have led to the development of resistance in insect 
pests (Gaganpreet et al., 2017). In Himachal Pradesh pesticides such as profenofos and chlorpyrifos have been used extensively by the farmers to control these major insect-pests of cauliflower crop. Since, the effect of insecticides is considered more toxic hence extra care should be taken to reduce the health hazards to the consumers. The application of these pesticides near to harvest can leave residues on the curds which may be harmful to the consumers (Banshtu et al., 2015).

Cauliflower is consumed as cooked or raw; hence chances of carrying pesticide residues to the consumers are more (Raj et al., 1991). Hence Pesticide residues in cauliflower are of major concern to consumers due to their negative health effects.

They have been found in both raw and processed fresh produce. There have been various reports suggesting use of different simple household processes in dislodging pesticide residues from food commodities thus making them safe for human consumption (Sharma et al., 1994; Aktar et al., 2009; Chavarri et al., 2005; Dejonckheere et al., 1996; Elkins, 1989; Krol et al., 2000; Schattenberg et al., 1996).

Operations such as Washing, peeling, blanching and cooking play a crucial role in the reduction of residues (Elkins, 1989; Kaushik et al., 2009). Each operation has a cumulative effect on the reduction of the pesticides (Geisman et al., 1975).

So in the present scenario it is very important that some pragmatic solution should be developed to tackle this problem of food safety. Food safety is an area of growing concern worldwide on account of its direct bearing on human health. The presence of harmful pesticide residues in food such as cauliflower has caused a great concern among the consumers. Therefore, the present investigations were contemplated with the objective to study the effect of different decontamination processes in curds for the reduction of profenofos and chlorpyrifos residues after its application on cauliflower crop in the field. Hence the techniques used in the present study focused on commercial and home processing of tomato and they included washing alone, washing with chemicals, cooking and washing followed by cooking.

\section{Materials and Methods}

\section{Chemicals and reagents}

Profex 50EC containing 50\% profenofos was obtained from M/S Nagarjuna Agrichem Ltd. and Lethal 20EC containing 20\% chlorpyrifos was obtained from M/S Insecticides (India) Ltd. and reagents like acetone, dichloromethane, hexane, toluene, sodium chloride, sodium sulfate anhydrous (AR grade), Celite 545 were all procured from M/S Merck Specialities, Mumbai.

Activated charcoal decolorizing powder was obtained from M/S Darmstadt, Germany. All common solvents were redistilled in an allglass apparatus before use.

\section{Field trials}

Cauliflower curds (Brassica oleracea var. botrytis L.) were raised during 2010 at Entomological Farm, Dr YS Parmar University of Horticulture and Forestry, Nauni, Solan, Himachal Pradesh following recommended agronomic practices (Anonymous, 2010). The experiment was conducted in randomized block design (RBD) with three replications for each treatment.

The first application of Profex 50EC (profenofos 50\%) @ $0.8 \mathrm{ml} / \mathrm{L}$ and Lethal 20EC (chlorpyrifos 20\%) @ 2.50ml/L were made at curd formation stage followed by 
second application at an interval of 15 days. In control plots, only water was sprayed. Pesticide was sprayed as foliar application in three replications with the help of a knapsack sprayer, fitted with a hollow cone nozzle.

\section{Sampling procedure}

Curd samples $(1 \mathrm{~kg})$ from each replication were collected randomly at 0 (2 hours after spray) and 3 days intervals after last foliar application. The samples from each replication were collected randomly, packed in bags and brought to the laboratory for processing.

\section{Decontamination processes}

Samples collected from the field were subjected to different decontamination processes viz. washing, cooking and washing followed by cooking (Patyal et al., 2004).

\section{Washing}

Cauliflower curds were washed under running tap water and hand rubbed for 2 minutes.

Cauliflower curds samples were dipped in lukewarm water $\left(50^{\circ} \mathrm{C}\right)$ for 5 minutes and then, placed on filter papers for drying.

Cauliflower curds samples were dipped in $2 \%$ $\mathrm{NaCl}(\mathrm{w} / \mathrm{v})$ solution for 5 minutes followed by tap water washing.

Cauliflower curds Samples were dipped in 2\% lukewarm salt solution (w/v) for 5 minutes followed by water washing.

Cauliflower curds samples were dipped in $0.05 \% \mathrm{HCl}(\mathrm{v} / \mathrm{v})$ for 5 minutes, followed by water wash.

Cauliflower curds samples were dipped in $2 \%$ (w/v) sodium hydroxide solution for 5 minutes, followed by washing with water.

\section{Cooking}

Open pan cooking: Unwashed samples from each replication were chopped and put in an open pan of 1 litre capacity containing $500 \mathrm{ml}$ water and boiled till softness (10-15 minutes).

Steam cooking: Samples were chopped and steamed for 5 minutes in a pressure cooker.

Microwave cooking: Curd samples were kept in microwave for 5 minutes for cooking at $1400 \mathrm{~W}$ power output.

\section{Washing followed by cooking}

Washing + cooking: Curd samples were first washed by hand rubbing under a stream of running tap water for 2 minutes, followed by boiling in an open pan of 1 litre capacity containing $500 \mathrm{ml}$ water till soft (10-15 minutes).

Washing + steam cooking: Samples were washed under running tap water and steamed for 5 minutes in a pressure cooker.

Washing + microwave cooking: Samples were first washed under the tap water and then, placed in microwave for 5 minutes for cooking at $1400 \mathrm{~W}$ power output.

After completing decontamination process, samples were extracted and cleaned up according to the method of Sharma (2007).

\section{Extraction and cleanup}

The samples were processed and analyzed at the Pesticide Residue Analysis Laboratory, Department of Entomology, Dr YS Parmar University of Horticulture and Forestry, Nauni, Solan, Himachal Pradesh.

Processed cauliflower curds samples were homogenised in a domestic mixture. 
A representative $100 \mathrm{~g}$ homogenised sample was taken up with $200 \mathrm{ml}$ acetone in a $500 \mathrm{ml}$ conical flask and kept for overnight. The extract was filtered through Buchner funnel by fitting a Whatman No. 1 filter paper. An aliquot of $60 \mathrm{ml}$ (30 g equivalent) of sample was transferred to 1 litre separatory flask and extracted with $200 \mathrm{ml}$ mixture of hexane and dichloromethane $(1: 1, \mathrm{v} / \mathrm{v})$. The lower aqueous phase was transferred to another 1 litre separatory funnel containing ten millilitre saturated sodium chloride solution and partitioned twice with $100 \mathrm{ml}$ dichloromethane. Lower aqueous phase was discarded and upper organic phase was pooled with first organic fraction. Pooled organic phase was passed through anhydrous sodium sulfate and evaporated to dryness at $45^{\circ} \mathrm{C}$ by using vacuum rotary evaporator. Finally, the residues were taken up in $3 \mathrm{ml}(1+2)$ acetone for cleanup. Profenofos and chlorpyrifos samples were cleaned up on charcoal column. Two millilitres of sample fraction of each was loaded in a charcoal column which was prepared by placing one inch layer of Celite 545, $6 \mathrm{~g}$ adsorbent mixture (1:4 w/w Charcoal: Celite 545) and then, overlaid with $2 \mathrm{~g}$ sodium sulfate. The column was eluted with $200 \mathrm{ml}$ of 2:1 acetone: dichloromethane mixture. Eluent was evaporated to dryness, residues were dissolved in $2 \mathrm{ml}$-hexane and $1 \mu \mathrm{l}$ was injected into a gas chromatograph.

\section{Residue estimation}

Residues of profenofos and chlorpyrifos were estimated by using Gas-Chromatograph (Agilent 6890N) having ECD detector and DB-5 Ultra Performance Capillary column (Cross-linked Methyl Silicon, length $30 \mathrm{~m}$, $0.25 \mathrm{~mm}$ internal diameter with $0.25 \mu \mathrm{m}$ film thickness). Oven temperature was programmed as: $100^{\circ} \mathrm{C}$ for 1 minute, $30^{\circ} \mathrm{C} /$ minute up to $150^{\circ} \mathrm{C}, 3^{\circ} \mathrm{C} /$ minute up to $205^{\circ} \mathrm{C}$ and finally $260^{\circ} \mathrm{C}$ at rate of $10^{\circ} \mathrm{C} /$ minute. Injection port and electron capture detector (ECD) temperature were kept at $250^{\circ} \mathrm{C}$ and $300^{\circ} \mathrm{C}$, respectively.

Profenofos and chlorpyrifos residues $(\mathrm{mg} / \mathrm{kg}$ ) were determined for each replication and then mean residues were calculated. Per cent relief from residues in each treatment was calculated from the mean residues, by the following equation:

$\%$ relief $=100-($ Residue in processed sample $(\mathrm{mg} / \mathrm{kg})$ / Residue in unprocessed sample $(\mathrm{mg} / \mathrm{kg}))$ X 100)

\section{Validation of analytical method}

Unprocessed samples from untreated plot were spiked with profenofos insecticide at $0.05,0.10,0.20,0.50$ and $1.00 \mathrm{mg} / \mathrm{kg}$ and for chlorpyrifos it was $0.01,0.05,0.10,0.50$ and $1.00 \mathrm{mg} / \mathrm{kg}$ fortified levels. Data presented in Table 1 depicts reliability of analytical method, as the recovery of insecticides was above 88 per cent. Recovery of profenofos was between $88.00-94.00 \%$ with relative standard deviation (RSD) of 0.044-0.679\% and for chlorpyrifos recovery was between 90.00-94.00\% with RSD 0.112-1.030\% (Table $1)$.

\section{Results and Discussion}

\section{Effect of Washing}

Washing is the most common form of processing which is a preliminary step in both household and commercial preparation. Loosely held residues of several pesticides are removed with reasonable efficiency by varied types of washing processes (Street, 1969). Washing of 0 day sampled cauliflower curds under running tap water provided $26.06 \%$ relief from profenofos residues whereas $36.17 \%$ relief was observed in 3 day old samples (Figure 1). After washing of chlorpyrifos treated cauliflower curds 
observations were recorded in 0, 3 and 7 days sampled curds and per cent relief were 35.44, 31.46 and 16.00, respectively (Figure 2). Aktar et al., (2010) reported that washing of cabbage head under running tap water removed 27.72-32.48\% quinalphos residues which are in accordance with my findings.

Similarly, Singh et al., (2004) also found that washing of okra fruits with tap water could remove the residues of cypermethrin to the extent of $36.25-42.76 \%$. The initial diazinon residue level $(0.822 \mathrm{ppm})$ on cucumbers was decreased by $22.3 \%$ by washing for 15 seconds rubbing under running water (Cengiz et al., 2006).

Lukewarm water washing of 0 day sampled cauliflower curds provided $28.34 \%$ relief from profenofos residues whereas $39.24 \%$ relief was observed in 3 days old samples (Fig. 1).

Similarly, in chlorpyrifos treated cauliflower curds observations were recorded on 0,3 and 7 days and 38.58, 36.85 and $16.00 \%$ relief was observed respectively (Fig. 2) which are in accordance with Kanta et al., (1998) who reported 7-38 per cent reduction of alphacypermethrin residues by lukewarm water washing of cauliflower curds.

Kumari (2008) also reported 32-100 per cent reduction of OP's insecticide residues by lukewarm water of cauliflower.

\section{Chemical washing}

Washing of treated cauliflower curds with sodium hydroxide and hydrochloric acid provided a good relief from profenofos and chlorpyrifos residues in comparison to washing with sodium chloride and lukewarm sodium chloride solution. It may be due to hydrolytic property of profenofos and chlorpyrifos in strong acids and alkalis (Tomlin, 1995). Sodium hydroxide provided
$70.30 \%$ and $67.18 \%$ relief from profenofos and chlorpyrifos, respectively. Dip treatment of cauliflower curds with hydrochloric acid gave $65.52 \%$ relief from profenofos and $61.17 \%$ from chlorpyrifos residues.

The present findings are in agreement with Patyal et al., (2004) who found that washing of treated apple fruits with $2 \%(\mathrm{w} / \mathrm{v}) \mathrm{NaOH}$ and $0.05 \%(\mathrm{v} / \mathrm{v}) \mathrm{HCl}$ gave 77.06 and $75.96 \%$, relief respectively from endosulfan residues.

Dipping of cauliflower curds samples in $2 \%$ sodium chloride solution (w/v) reduced profenofos and chlorpyrifos residues to $41.29 \%$ and $41.46 \%$ whereas lukewarm sodium chloride solution reduced residues to $55.29 \%$ and $48.88 \%$ respectively which is in agreement with the findings of Mukherjee et al., (2006) also observed that dipping of cauliflower curds in $1 \%$ brine solution followed by washing reduced the residues by $39.6 \%$ while in case of hot $1 \%$ brine solution, the reduction was $55.0 \%$.

\section{Cooking}

Application of heat to the food commodities is commonly done through ordinary cooking, pressure cooking, microwave cooking, frying, sterilization and canning.

The effect of different cooking processing on removal of profenofos and chlorpyrifos residues in cauliflower was studied (Figure 1 and 2). In all of the processes, pressure cooking was found to be most effective than the other processes.

Pressure cooking reduced the residues up to $67.57 \%$. These results are in accordance with the findings Muthukumar et al., (2010) who also reported that pressure cooking was the most effective in reducing both $\alpha$ - and $\beta$ endosulfan by $64.59 \%$ and $61.60 \%$ as compared to boiling and microwave cooking. 
Table.1 Recovery of profenofos and chlorpyrifos from cauliflower curds

\begin{tabular}{|c|c|c|c|}
\hline Insecticides & \multicolumn{3}{|c|}{ Cauliflower curds } \\
\hline \multirow{2}{*}{$\begin{array}{c}\text { Fortification level, } \\
\text { (mg/kg) }\end{array}$} & Mean recovery (\%) & $\begin{array}{c}\text { Relative standard } \\
\text { deviation (\% RSD) }\end{array}$ \\
\hline Profenofos & 0.05 & 88.00 & 0.679 \\
\hline 0.10 & 89.00 & 0.298 \\
\hline 0.20 & 90.00 & 0.195 \\
\hline 0.50 & 93.00 & 0.242 \\
\hline Chlorpyrifos & 1.00 & 94.00 & 0.044 \\
\hline 0.01 & 90.00 & 1.030 \\
\hline 0.05 & 92.00 & 0.987 \\
\hline 0.10 & 93.00 & 0.858 \\
\hline 0.50 & 91.00 & 0.178 \\
\hline & 1.00 & 94.10 & 0.112 \\
\hline
\end{tabular}

Fig.1 Per cent relief from profenofos residues from different decontamination processes $(\mathrm{W}=$ Tap water washing, $\mathrm{LW}=$ Luke warm, $\mathrm{OPC}=$ Open pan cooking, $\mathrm{PC}=$ Pressure cooking, $\mathrm{MC}=$ Microwave cooking)

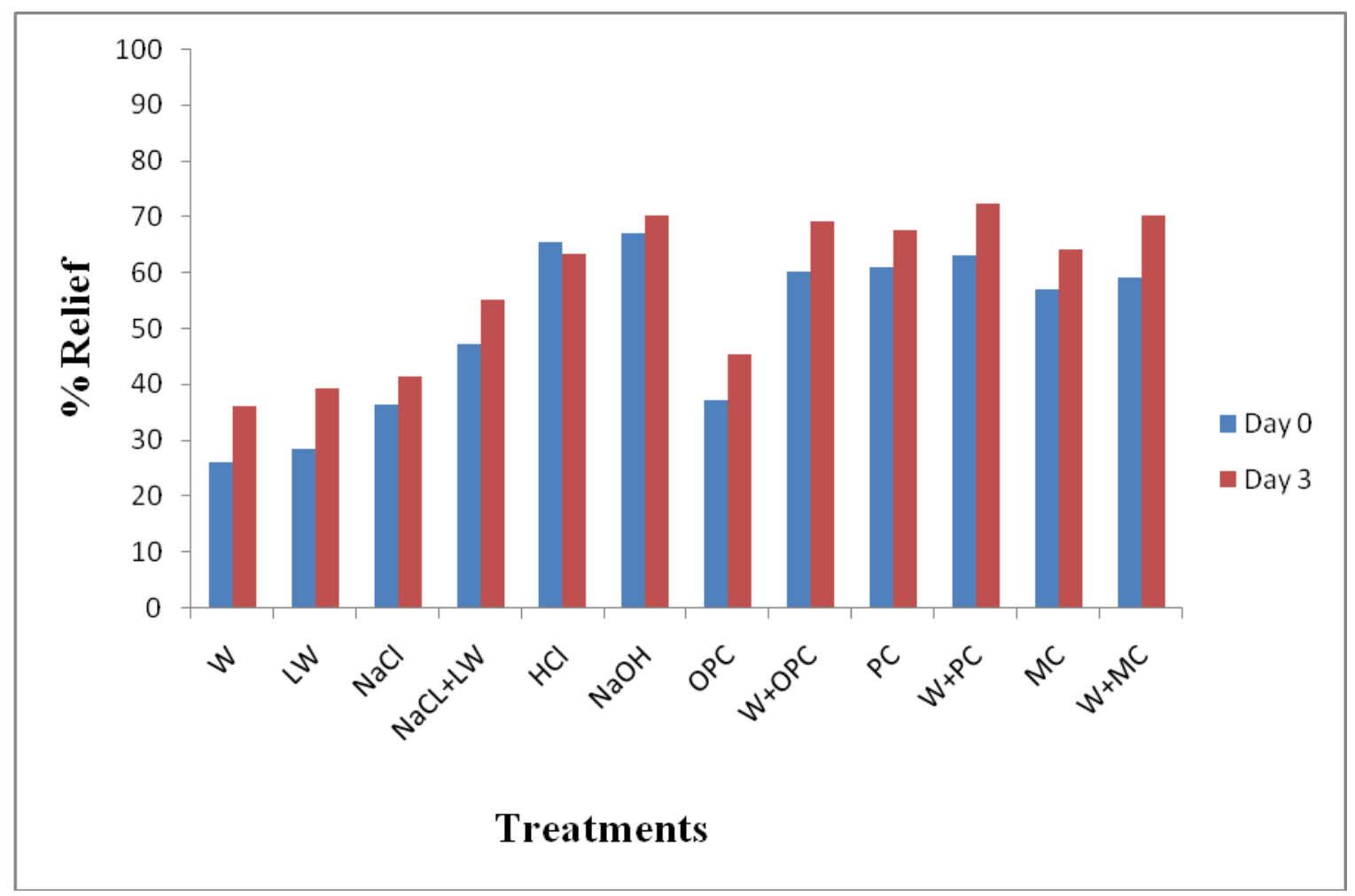


Fig.2 Per cent relief from chlorpyrifos residues from different decontamination processes (W= Tap water washing, $\mathrm{LW}=$ Luke warm, $\mathrm{OPC}=$ Open pan cooking, $\mathrm{PC}=$ Pressure cooking, $\mathrm{MC}=$ Microwave cooking)

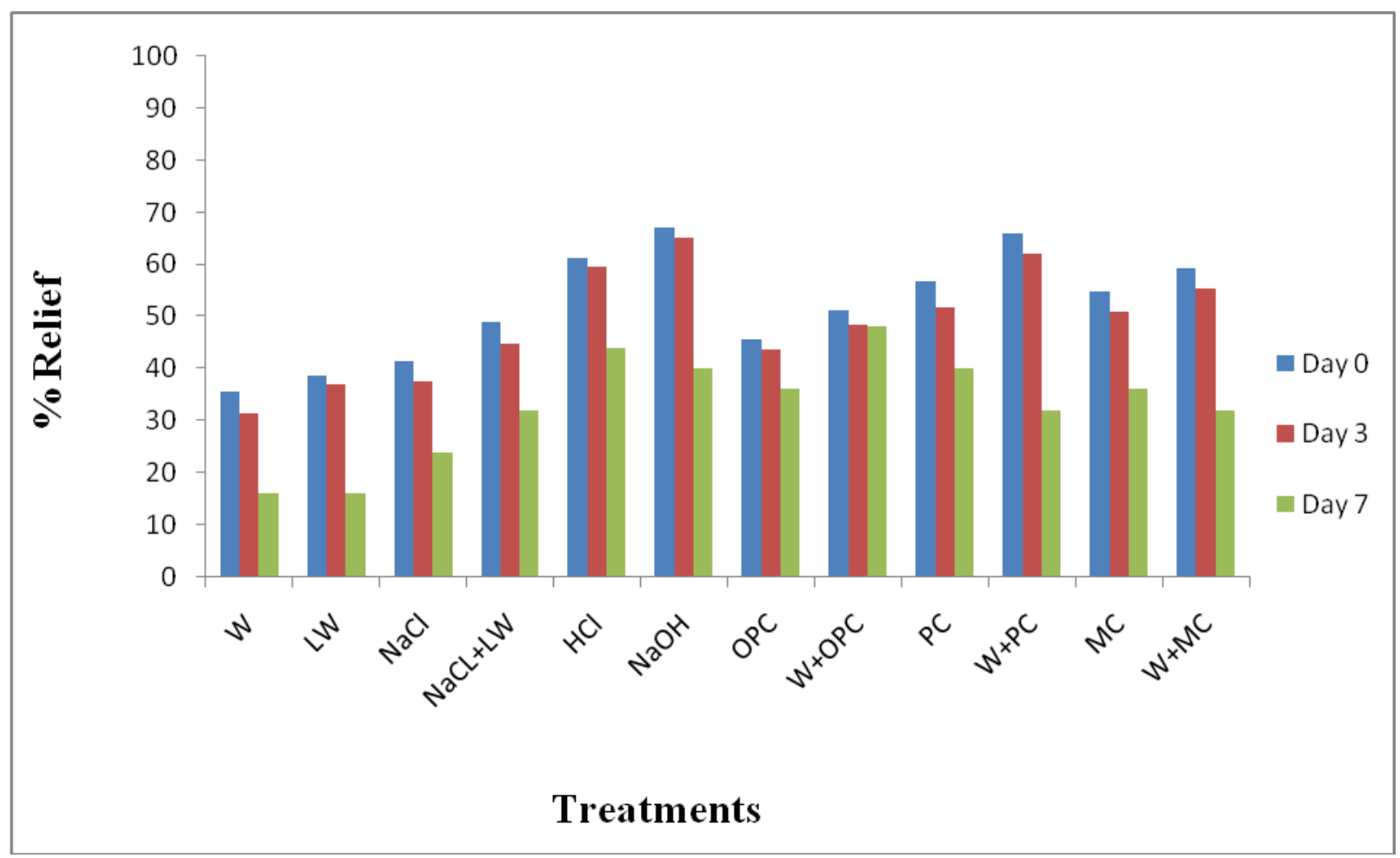

Cooking of cauliflower curds in open pan or under pressure or in the microwave resulted in $36-68 \%$ relief from profenofos and chlorpyrifos residues. The findings are in agreement with Dikshit (2001) who observed that process of steaming dislodged the cypermethrin residues by $63-74 \%$ on stored pulses treated at 3 and $5 \mathrm{mg} / \mathrm{kg}$ levels. The disappearance of pesticide residues from boiling extract could be due to decomposition by the effect of heat, the stronger adsorption of pesticide onto plant tissues and or/the poor solubility of pesticides in water (Abou and Abou 2001; Ali, 1983). Walia et al., (2010) reported that microwave cooking reduced cypermethrin residues to the extent of 40.89 per cent in brinjal sprayed at 0.001 per cent concentration. Hence, processes involving heat can increase volatilization, hydrolysis or other chemical degradation and thus, reduce residue levels (Holland et al., 1994).

\section{Washing followed by cooking}

Washing is generally the first step in various types of treatments which are given to food commodities in combinations like washing followed by cooking, washing and drying, washing and peeling and washing, peeling and juicing to allow for effective decontamination from pesticides (Kaushik et al., 2009).

Washing of cauliflower curds followed by cooking lead to more than $72 \%$ removal of profenofos and chlorpyrifos residues (Figure 1 and 2). Similarly, Mukherjee et al., 2006 also reported that washing of cauliflower heads under running tap water removed $27.9 \%$ chlorpyrifos residues, cooking reduced residues to $41.4 \%$ and washing + cooking further reduced residues to $66.7 \%$. Aktar et al., (2010) also reported that washing plus 
cooking of cabbage heads reduce more quinalphos residues (66.45-68.19\%) in comparison to washing alone (41.30-45.20\%).

A critical analysis of whole decontamination data revealed that the washing plus pressure cooking removed much higher residues from contaminated fruits as compared to the simple washings. Although, sodium hydroxide and hydrochloric acid treatments were superior over all other decontamination processes but such treatments can be used in the industries where large quantity of vegetables are processed for decontamination. Washing of vegetables with water followed by pressure cooking removed maximum residues up to $72 \%$ as compared to the other processes and proved good household practice.

\section{References}

Abou AAAK and Abou DMA. 2001. Pesticide residues in some Egyptian spices and medicinal plants as affected by processing. Food Chemistry 72: 439-445

Aktar MW, Dwaipayan S, Mariappan P and Ashim C. 2009. Risk assessment and degradation of an insecticide (chlorpyriphos): a decontamination study under different culinary processes in/on cabbage. Kasetsart Journal Natural Sciences 43(2): 231-238

Aktar MW, Dwaipayan S, Purkait S and Chowdhury A. 2010. Risk assessment and decontamination of quinalphos under different culinary processes in cabbage. Environmental Monitoring and Assessment 163: 369-377

Ali SL. 1983. Bestimmung der pestiziden Ruckstande und anderer bedenklicher eruntreinigungen-wie toxische Metallspuren in Arzneipflanzen1. Mitt: Pestizid-Ruckstande in Arzneidrofen. Pharmazie Industrial 45: 1154-1156
Anonymous. 2010. Package and Practices for Vegetable Crops. Directorate of Extension Education, Dr. Y.S Parmar University of Horticulture and Forestry, Solan. p. 294

Banshtu T, Patyal SK and Chandel RS. 2015. Persistence of profenofos and cypermethrin in tomato grown under mid hill conditions of Himachal Pradesh. The Ecoscan 9(3\&4): 755-759

Bhalla OP and Pawar AD. 1977. A survey study of insect and non-insect pests of economic importance in Himachal Pradesh. Tiku and Tiku, Kitab Mahal, $80 \mathrm{p}$.

Cengiz MF, Certel M, Karakas $\mathrm{B}$ and Gocmen, H. 2006. Residue contents of DDVP (Dichlorvos) and diazinon applied on cucumbers grown in greenhouses and their reduction by duration of a pre-harvest interval and post-harvest culinary applications. Food Chemistry 98: 127-135.

Chandra S, Kumar M, Mahindrakar AN and Shinde LP. 2015. Effects of household processing on reduction of pesticide residues in brinjal and okra. International Journal of Advances in Pharmacy, Biology and Chemistry 4(1): 98-102

Chavarri MJ, Herrera A and Arino A. 2005. The decrease in pesticides in fruit and vegetables during commercial processing. International Journal of Food Science and Technology 40(2): 205-211

Dejonckheere W, Steurbaut W, Drieghe S, Verstraeten R and Braeckman H. 1996. Pesticide residue concentrations in the Belgian total diet, 1991-1993. Journal of AOAC International 79(2): 520-528

Dikshit AK. 2001. Persistence of cypermethrin on stored pulses and its decontamination. Pesticide Research Journal 13(2): 141-146 
Elkins ER. 1989. Effect of commercial processing on pesticide residues in selected fruits and vegetables. Journal of the Association of Official Analytical Chemists 72(3): 533-535

Gaganpreet SB, Patyal SK and Banshtu T. 2017. Persistence of acephate, profenofos and triazophos residues in brinjal fruits and soil. The Bioscan 12(1): 115-119

Geisman JR, Gunther FA and Gunther JD. (eds.). 1975. Reduction of pesticide residues in food crops by processing. Residue reviews. Residues of pesticides and other contaminants in the total environment 54, pp. 43-54

Holland PT, Hamilton D, Ohlin B, and Skidmore MW. 1994. Effects of storage and processing on pesticide residues in plant products. IUPAC Reports on Pesticides 31. Pure and Applied Chemistry 66(2): 335-356

Kanta M, Kumari B and Kathpal TS. 1998. Persistence and decontamination of alphamethrin residue in cauliflower at two different temperatures. Pesticide Research Journal 10(2): 246-250

Kaushik G, Satya S and Naik SN. 2009. Food processing a tool to pesticide residue dissipation -a review. Food Research International 42: 26-40

Krol WJ, Arsenault TL, Pylypiw HM and Mattina MJI. 2000. Reduction of pesticide residues on produce by rinsing. Journal of Agricultural and Food Chemistry 48(10): 4666-4670

Kumari B. 2008. Effects of household processing on reduction of pesticide residues in vegetables. Journal of Agricultural and Biological Science 3(4): 46-51

Mukherjee P, Kole RK, Bhattacharyya A and Banerjee H. 2006. Reduction of chlorpyrifos residues from cauliflower by culinary processes. Pesticide Research Journal 18(1): 101-103
Muthukumar M, Sudhakar RK, Reddy NC, Reddy KK, Reddy GA, Reddy JD and Kondaiah N. 2010. Detection of cyclodiene pesticide residues in buffalo meat and effect of cooking on residual level of endosulfan. Journal of Food Science and Technology 47(3): 325-329

Patel BA, Shah PG, Raj MF, Patel BK, Patel JA and Talathi JG. 1999. Chorpyriphos residues in/on cabbage and brinjal. Pesticide Research Journal 11(2): 194196

Patyal SK, Lakhanpal AK, Nath A and Sharma PC. 2004. Effect of processing on endosulfan residues in apple. Journal of Food Science and Technology Mysore 41(3): 316-319

Raj MF, Shah PG, Patel BK and Patel JR. 1991. Endosulfan residues in tomato and brinjal fruits. Pesticide Research Journal 3(2): 135-138

Regupathy A, Habcebullah B and Balasubramania M. 1985. Dissipation of insecticides applied to control Plutella xyllostella citrus and Spodoptera litura, Faber in cauliflower. Pesticides 19(9): 53

Schattenberg HJ, Geno PW, Hsu JP, Fry WG and Parker RP. 1996. Effect of household preparation on levels of pesticide residues in produce. Journal of AOAC International 79(6): 1447-1453

Sharma ID, Nath A and Dubey JK. 1994. Persistence of mancozeb (Dithane M45) in some vegetables and efficacy of decontamination processes. Journal of Food Science and Technology 31(3): 215-218

Sharma KK. 2007. Pesticide Residue Analysis Manual. Directorate of Information and Publications of Agriculture, Indian Council of Agricultural Research, Krishi Anusandhan Bhavan, Pusa, New Delhi, p. 294

Sharma PL and Bhalla OP. 1964. Survey study of insect pests of economic 
importance in Himachal Pradesh. Indian Journal of Entomology 26: 318-331

Sharma VK. 1975. Survey of insect pests of, off season tomato under mid hill conditions. M.Sc. Thesis submitted to Himachal Pradesh University Shimla, India. 1-126 pp.

Singh SP, Kiran K, Sanjay K and Tanwar RS. 2004. Dissipation and decontamination of cypermethrin and fluvalinate residues in okra. Pesticide Research Journal 16(2): 65-67
Street JC. 1969. Methods of removal of pesticide residues. Canadian Medical Association Journal 100: 154-160.

Tomlin C. 1995. The Pesticide Manual. A World Compendium. British Crop Protection Council, p. 388

Walia S, Boora P and Kumari B. 2010. Effect of processing on dislodging of cypermethrin residues on brinjal. Bulletin of Environmental Contamination and Toxicology 84(4): $465-468$

\section{How to cite this article:}

Tanuja Banshtu, Surender Kumar Patyal and Sarswati Negi. 2018. Effect of Processing on Profenofos and Chlorpyrifos Residues in Cauliflower Curds. Int.J.Curr.Microbiol.App.Sci. 7(10): 2610-2619. doi: https://doi.org/10.20546/ijcmas.2018.710.303 